\title{
A NEW CRYSTALLINE CALCIUM CHLORIDE COMPOUND OF $\alpha-d$-GULOSE AND ITS ROTATION AND MUTAROTA- TION IN AQUEOUS SOLUTION
}

\author{
By Horace S. Isbell
}

\section{ABSTRACT}

The optical rotation of $\alpha-d$-gulose is determined from a new crystalline calcium chloride compound of $\alpha-d$-gulose. The calcium chloride is removed from the compound very completely and quickly by means of dry silver oxalate, giving a pure gulose solution which exhibits mutarotation.

The equilibrium rotation of $\alpha$-d-gulose $\mathrm{CaCl}_{2} \cdot \mathrm{H}_{2} \mathrm{O}$ varies widely with the concentration of the solution. It is shown that concentrated solutions upon dilution with water exhibit mutarotation which indicates that the equilibrium of the various forms of the sugar in solution is altered by a change in the concentration of calcium chloride. It is believed that this equilibrium disturbance is caused by the dissociation of the double compound of $d$-gulose and calcium chloride, which is further illustrated by the optical rotacions of alcoholic solutions.

\section{CONTENTS}

I. Introduction

II. $\alpha$-d-Gulose calcium chloride

1. Optical rotation of $\alpha-d$-gulose

2. Equilibrium rotation of $d$-gulose $\mathrm{CaCl}_{2} \cdot \mathrm{H}_{2} \mathrm{O}$

3. Variations in the equilibria between the different forms of the sugar in solution.

4. Dissociation of $\alpha$ - $d$-gulose $\mathrm{CaCl}_{2}$

5. Crystallization of $\alpha$ - $d$-gulose $\mathrm{CaCl}_{2} \cdot \mathrm{H}_{2} \mathrm{O}$

III. Experimental details 1 . Preparation of crude $d$-gulose

1. Preparation of crude $d$-gulose

3. Preparation of $\alpha$-d-gulose $\mathrm{CaCl}_{2} \cdot \mathrm{H}_{2} \mathrm{O}$ from the gulose sirup obtained from the phenylhydrazone

4. Optical rotation of $\alpha-d$-gulose

5. Preparation of $\alpha-d$-gulose $\mathrm{CaCl}_{2} \cdot \mathrm{H}_{2} \mathrm{O}$ from the reduction product of gulonic lactone...

IV. Summary product of gulonic lactone

\section{INTRODUCTION}

The determination of the optical rotation of any of the aldohexoses, which have not yet been obtained in the crystalline state, is of importance. Only three types of the aldohexose sugars (glucose, galactose, and mannose) have been obtained in crystalline form, and their rotations measured. In order to complete the data for calculating the optical rotations of the different asymmetric carbon atoms in the aldohexose sugars ${ }^{1}$ the rotation of a fourth aldohexose was necessary. One of the less known hexose sugars, $d$-gulose, may be obtained as a pure sirup by the Kiliani ${ }^{2}$ synthesis from xylose. A semicommercial

1 H. S. Isbell, B. S. Jour. Research, 3, p. 1041; 1929.

2 Kiliani, Ber., is, p. 3066; 1885. 
method for the preparation of xylose has been developed at the National Bureau of Standards ${ }^{3}$ so that sugar is now available in large quantities, which makes the $d$-gulose series a particularly attractive field for investigation. ${ }^{4} d$-gulose was first prepared by Fischer and Stahel ${ }^{5}$ by the reduction of gulonic lactone with sodium amalgam. They obtained a crude gulose sirup from which a crystalline phenylhydrazone was prepared. This compound was subsequently used for the purification of the sugar by Blanksma and van Ekenstein ${ }^{6}$ who removed the phenylhydrazine with benzaldehyde. Although they obtained a relatively pure product they were unable to bring the pure gulose sirup to crystallization. Subsequently by the same method other investigators ${ }^{7}$ including the author, have obtained similar results. Hence, it was evident that a radical departure from the previous method for the purification of the sugar was desirable. This led to the consideration of the coordination compounds of the sugars with inorganic salts. Recently J. K. Dale ${ }^{8}$ prepared several new crystalline calcium chloride compounds of various sugars whose molecular rotations agree approximately with the rotations of the corresponding crystalline sugars. In the light of Dale's work the author decided to attempt the preparation of a calcium chloride compound of $d$-gulose with the object of obtaining a crystalline derivative which would serve to establish some of the relations between structure and optical rotation in the hexose series.

\section{II. $\alpha$ - $d$-GULOSE CALCIUM CHLORIDE}

A crystalline calcium chloride compound was obtained upon evaporating in vacuo an aqueous solution of $d$-gulose containing about two molecular equivalents of calcium chloride. The new substance is dextrorotatory and mutarotates to the left indicating that it is an alpha ${ }^{9}$ form of the sugar. This is the first crystalline compound which can be definitely assigned to the $\alpha-d$-gulose series. As shown in Figure 1, it crystallizes in colorless prisms. It was shown to be a derivative of $d$-gulose by the separation of gulonic lactone in good yield after the oxidation of the sugar with bromine water. The oxidation was conducted according to the method devised by C. S. Hudson and the author, ${ }^{10}$ and will be published in a subsequent paper.

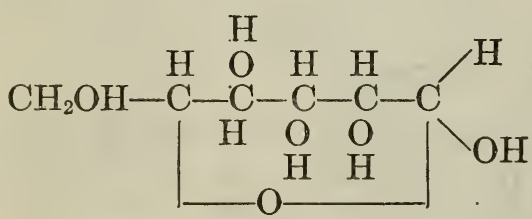

$\alpha$-d-gulose $(1,5)$

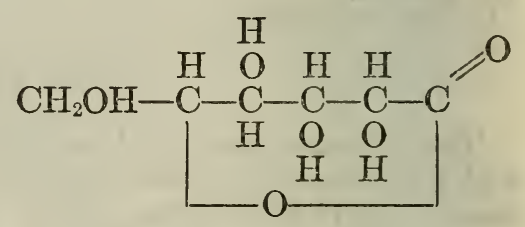

$d$-gulonic $(1,5)$ lactone.

\footnotetext{
3 Hall, Slater, and Acree, B. S. Jour. Research, 4, p. 329; 1930.

4 Originally a study of the $d$-gulose series was projected by C. S. Hudson, who has subsequently resigned from this bureau.

Fischer and Stahel, Ber.. 21, p. 528; 1891.

- Blanksma and van Ekenstein, Chemisch Weekblad, 5, p. 777; 1908.

7 LaForge, J. Biol. Chem., 41, p. 251; 1920.

8 Dale, B. S. Jour. Research, 3, p. 459; 1929; also J. Am. Chem. Soc., 51, p. 2225; 1929.

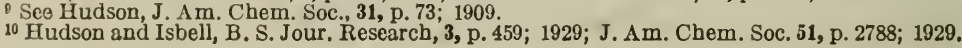




\section{B. S. Journal of Research, RP226}

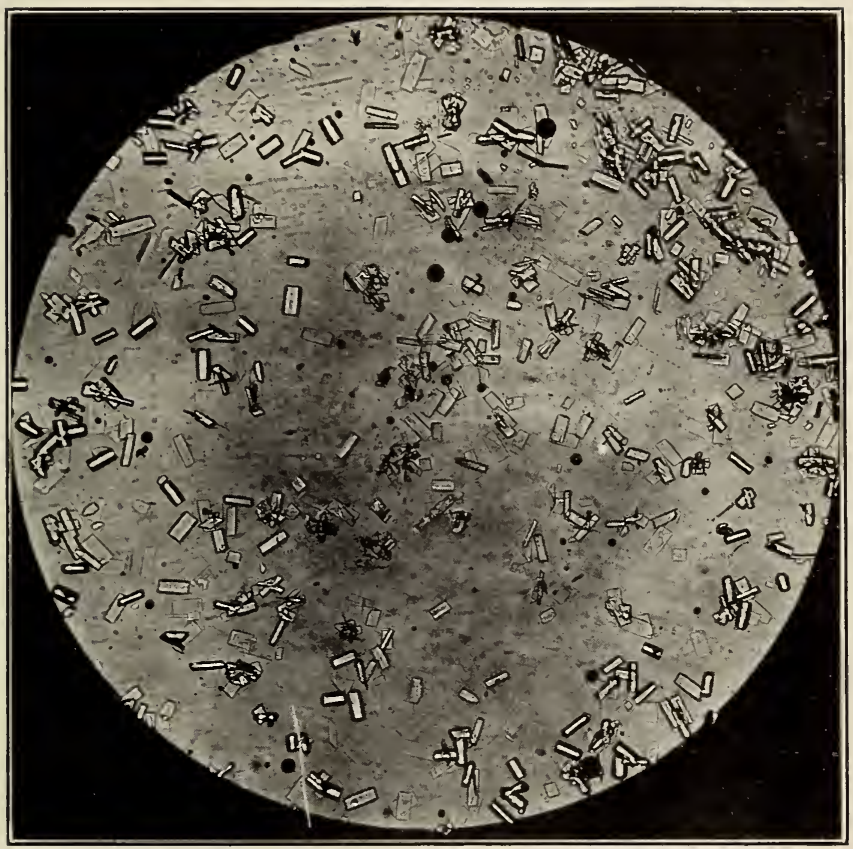

Figure 1.-Photomicrograph of $\alpha$ - $d$-gulose $\mathrm{CaCl}_{2} \cdot \mathrm{H}_{2} \mathrm{O}$ 
The calcium chloride compound has served for estimating the optical rotation of $\alpha$-d-gulose; and has revealed some interesting properties relating to the influence of calcium chloride on the equilibirum of the different forms of the sugar in solution.

\section{OPTICAL ROTATION OF $\alpha$-d-GULOSE}

The optical rotation of $\alpha-d$-gulose was obtained from a freshly prepared solution of $\alpha$ - $d$-gulose $\mathrm{CaCl}_{2} \cdot \mathrm{H}_{2} \mathrm{O}$ after removing the calcium chloride with finely powdered silver oxalate. By that reagent the calcium chloride is removed very quickly and completely, and the resulting solution exhibits mutarotation. The mutarotation constant $\left(k_{1}+k_{2}=0.021\right)$ for the solution agrees with the mutarotation constant for $\alpha$-d-gulose $\mathrm{CaCl}_{2} \cdot \mathrm{H}_{2} \mathrm{O}\left(k_{1}+k_{2}=0.019\right)$. These values are also close to the value given by $d$-mannose $\left(k_{1}+k_{2}=0.019\right){ }^{11}$ the sugar which resembles $d$-gulose most closely. Since the rate of mutarotation of the pure gulose solution and the rate of mutarotation of the calcium chloride compound are nearly equal, it is possible to extrapolate the rotations observed after removing the calcium chloride to zero time and thus obtain the initial rotation of $\alpha$ - $d$-gulose. The initial specific rotation of $\alpha$-d-gulose was found by this method to be $+61.6^{\circ}$ (Table 1) which is equivalent to $[M]_{D}^{20}=+11,100$. The initial specific rotation of $\alpha$-d-gulose $\mathrm{CaCl}_{2} \cdot \mathrm{H}_{2} \mathrm{O}$ was found to be +37.7 (Table 3) which is equivalent to $[M]_{D}^{20}=+11,650$. The difference in the molecular rotations just given appears to be only slightly more than the experimental error. Since the calcium chloride may increase the rotation of the sugar, the value obtained after removing the calcium chloride was chosen for the rotation of $\alpha$ - $d$-gulose and was used in a previous publication ${ }^{12}$ for the calculation of the optical rotatory values for the various asymmetric carbon atoms in the aldohexose sugars.

${ }^{11}$ Hudson and Sawyer, J. Am. Chem. Soc. 39, p. 475; 1917; also Dale, B. S. Jour. Research, 3, p. 464; 1929.

12 See footnote 1, p. 741 . 


\section{TABLE 1.-Mutarotation of $\alpha$-d-gulose in water}

[1.2238 $\mathrm{g}$ of $\alpha$-d-gulose $\mathrm{CaCl}_{2} \cdot \mathrm{H}_{2} \mathrm{O}$ were shaken with $2 \mathrm{~g}$ dry silver oxalate in $24.9550 \mathrm{~g}$ water; after filtration the rotations were read in a 2 -dm tube. Density of the solution at $20^{\circ}$ was $1.0095 \mathrm{~g} / \mathrm{ml}$. Calculated concentration $=0.7130 \mathrm{~g}$ gulose in $25.50 \mathrm{ml}$. $T=20^{\circ} \pm 0.5^{\circ}$ ]

\begin{tabular}{|c|c|c|c|}
\hline $\begin{array}{l}\text { Time after the addition of water } \\
\text { (in minutes) }\end{array}$ & $\begin{array}{l}\text { Observed sac- } \\
\text { charimeter } \\
\text { reading }\end{array}$ & $\begin{array}{l}\quad[\alpha]_{D}^{20} \\
\text { Calculated }{ }^{1} \text { for } \\
\text { for the gulose } \\
\text { constituent }\end{array}$ & $k_{1}+k_{2}{ }^{2}$ \\
\hline $\begin{array}{l}0 \\
0 \\
10\end{array}$ & $\begin{array}{r}{ }^{\circ} S \\
+6.43 \\
+5.50 \\
+4.60 \\
+3.80 \\
+3.13 \\
+2.35 \\
+1.80 \\
+1.22 \\
-.02 \\
-.95 \\
-2.25 \\
-3.03 \\
-3.50 \\
-4.27\end{array}$ & $\begin{array}{c}3+61.6) \\
+39.8 \\
+34.0 \\
+28.5 \\
+23.5 \\
+19.4 \\
+14.5 \\
+11.1 \\
+7.6 \\
-.1 \\
-5.9 \\
-13.9 \\
-18.8 \\
-21.7 \\
-26.4\end{array}$ & $\begin{array}{l}0.020 \\
.020 \\
.020 \\
.020 \\
.021 \\
.020 \\
.021 \\
.021 \\
.021 \\
.021 \\
.021 \\
.021\end{array}$ \\
\hline & & & .0206 \\
\hline
\end{tabular}

${ }^{1}[\alpha] \frac{t}{D}=\frac{{ }^{\circ} S \times 0.3462}{l C}$, where $t$ designates the temperature of the measurement, ${ }^{\circ} S$ is the observed saccharimeter reading, 0.3462 is the conversion factor, $l$ the length of the solution in $\mathrm{dm}, C$ its concentration in $g$ per $\mathrm{ml}$ at $t^{\circ}$ which is equal to $p d$, where $p$ is its concentration in weight per cent and $d$ its density in $\mathrm{g} / \mathrm{ml}$ at $t^{\circ}$. (International Critical Tables, Vol. II, p. 334.)

2 The numerical value for the mutarotation constant, $k_{1}+k_{2}=\frac{1}{T} \log _{10} \frac{r_{0}-r_{\infty}}{r-r_{\infty}}$ is calculated for all the observed values using the first observed value for $r_{0}$ and the final or constant value for $r \infty$.

3 The initial rotation, which is placed in parentheses, is calculated by means of the mutarotation constant using the average numerical value, $k_{1}+k_{2}=0.0206$. If we let the unknown initial rotation be $r_{0}$, since the values of $r(+39.8)$ at the time, $t(6 \mathrm{~min}$.) and the constant rotation, $r \infty(-26.4)$, are known, the equation, $k_{1}+k_{2}=\frac{1}{t} \log _{10} \frac{r_{0}-r_{\infty}}{r-r_{\infty}}$, is easily solvad for $r_{0}(+61.6)$, the initial rotation. This value for $r_{0}$ is the extrapolated value for the rotation of the substance at zero time or at the moment at which it was put in solution. It is not the value used to calculate the numerical value of $k_{1}+k_{2}$.

\section{TABLE 2.-Mutarotation of $\alpha$-d-gulose $\mathrm{CaCl}_{2} \cdot \mathrm{H}_{2} \mathrm{O}$ in water}

[Concentration $=1.2886 \mathrm{~g}$ of compound in $25 \mathrm{ml}$ of solution; tube length, $2 \mathrm{dm} ; T=20^{\circ} \pm 0.5^{\circ}$

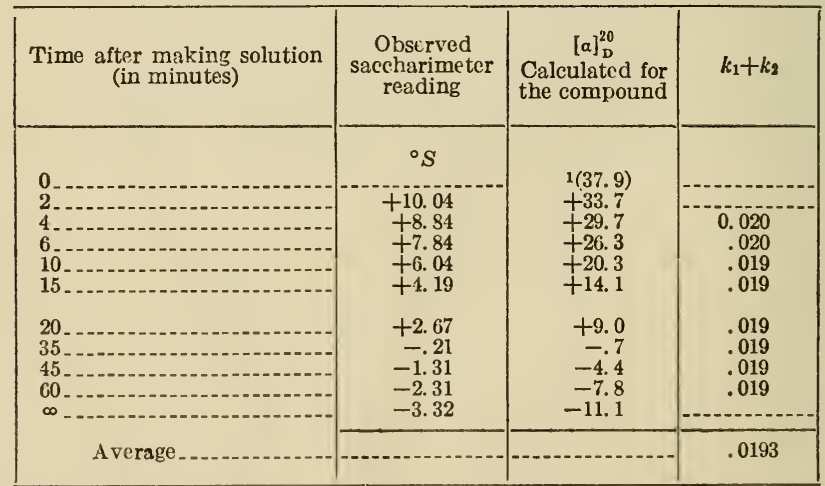

1 Calculated as given under Table 1 , above, using the following values: $k_{1}+k_{2}=0.0193 ; r=+33.7^{\circ}: r \infty=$ $-11.1^{\circ} ; t=2$. 
TABLE 3.-Mutarotation of $\alpha$-d-gulose $\mathrm{CaCl}_{2} \cdot \mathrm{H}_{2} \mathrm{O}$ in water

[Concentration $=2.6592 \mathrm{~g}$ of $\alpha$ - $d$-gulose $\mathrm{CaCl}_{2} . \mathrm{H}_{2} \mathrm{O}$ in $25 \mathrm{ml}$ of solution; tubc length, $2 \mathrm{dm} ; T=18.5 \pm 0.5^{\circ} \mathrm{O}$.]

\begin{tabular}{|c|c|c|c|}
\hline $\begin{array}{l}\text { Time after making solution } \\
\text { (in minutes) }\end{array}$ & $\begin{array}{l}\text { Observed } \\
\text { saceharimeter } \\
\text { reading }\end{array}$ & $\begin{array}{c}{[a]_{D}^{18.5}} \\
\text { of compound }\end{array}$ & $k_{1}+k_{2}$ \\
\hline $\begin{array}{l}0 \\
5 \\
8 \\
17 \\
22 \\
30 \\
41\end{array}$ & $\begin{array}{l}{ }^{\circ} S \\
+18.03 \\
+15.28 \\
+9.18 \\
+6.58 \\
+3.48 \\
+.13 \\
-2.72 \\
-4.47\end{array}$ & $\begin{array}{l}1(+37.7) \\
+29.3 \\
+24.9 \\
+14.9 \\
+10.7 \\
+5.7 \\
+.2 \\
-4.4 \\
-7.3\end{array}$ & $\begin{array}{l}0.019 \\
.018 \\
.018 \\
.018 \\
.018 \\
.017\end{array}$ \\
\hline Average & & & .0180 \\
\hline
\end{tabular}

1 Calculated as given under Table 1, p. 744, using the following values: $k_{1}+k_{2}=0.018 ; r=+29.3^{\circ} ; r \infty=$ $-7.3^{\circ} ; t=5$.

TABLE 4.-Mutarotation of $\alpha$-d-gulose $\mathrm{CaCl}_{2} \cdot \mathrm{H}_{2} \mathrm{O}$ dissolved in aqueous 5 per cent calcium chloride solution

[Concentration $=0.5536 \mathrm{~g} \alpha$-d-gulose $\mathrm{CaCl}_{2} . \mathrm{H}_{2} \mathrm{O}$ in $25 \mathrm{ml}$ of solution in which $1.25 \mathrm{~g} \mathrm{CaCl}_{2} .2 \mathrm{H}_{2} \mathrm{O}$ had been previously dissolved; length of tube, $2 \mathrm{dm} ; T=20^{\circ} \pm 0.5^{\circ}$ )

\begin{tabular}{|c|c|c|c|}
\hline $\begin{array}{l}\text { Time after making solution } \\
\text { (in minutes) }\end{array}$ & $\begin{array}{l}\text { Observed } \\
\text { saecharimeter } \\
\text { reading }\end{array}$ & $\begin{array}{c}{[a]_{D}^{20}} \\
\text { of compound }\end{array}$ & $k_{1}+k_{2} 1$ \\
\hline & ${ }^{\circ} S$ & $2(30-5)$ & \\
\hline $\begin{array}{l}3 \\
4 \\
6\end{array}$ & $\begin{array}{r}+2.76 \\
+2.26 \\
+1.46 \\
+.86\end{array}$ & $\begin{array}{r}21.6 \\
17.7 \\
11.4 \\
6.7\end{array}$ & $\begin{array}{l}0.068 \\
.068 \\
.069\end{array}$ \\
\hline 10 & $\begin{array}{l}+.38 \\
+.06 \\
-.24 \\
-.54 \\
-.71\end{array}$ & $\begin{array}{r}3.0 \\
.5 \\
-1.9 \\
-4.2 \\
-5.6\end{array}$ & $\begin{array}{l}.072 \\
.073 \\
.072 \\
.077\end{array}$ \\
\hline A verage. & & & .070 \\
\hline
\end{tabular}

1 The value of $k_{1}+k_{2}$ in this experiment is larger than the value which was obtained for a water solution (Table 3). C. P. ealcium ehloride usually contains a trace of alkali whieh aecounts for this larger value. 2 Caleulated as given under Table $1, \mathrm{p}$. 744, using the following values: $k_{1}+k_{2}=0.070: r=+21.6 ; t=3$ min.; $r \infty=-5.6$.

\section{TABLE 5.-Mutarotation of d-gulose after dilution with water and with aqueous $\mathrm{CaCl} l_{2}$}

[ $5 \mathrm{ml}$ portions of a solution ${ }^{1}$ eontaining $3.1740 \mathrm{~g}$ of $d$-gulose per $100 \mathrm{ml}$ were diluted to $25 \mathrm{ml}$ (1) with 5 per cent calcium ehloride solution, and (2) with water. The rotations were then read]

\begin{tabular}{|c|c|c|c|c|c|}
\hline \multicolumn{3}{|c|}{ Diluted with 5 per cent $\mathrm{CaCl}_{2}$ solution ${ }^{2}$} & \multicolumn{3}{|c|}{ Diluted with water } \\
\hline $\begin{array}{l}\text { Time after } \\
\text { adding } \mathrm{CaCl}_{2} \\
\text { solution } \\
\text { (in minutes) }\end{array}$ & $\begin{array}{l}\text { Observed sac- } \\
\text { eharimeter } \\
\text { reading } \\
\text { (2 dm tube) }\end{array}$ & $\begin{array}{c}{[\alpha]_{\mathrm{D}}^{20}} \\
\text { of } d \text {-gulose }\end{array}$ & $\begin{array}{l}\text { Time after } \\
\text { adding water } \\
\text { (in minutes) }\end{array}$ & $\begin{array}{c}\text { Observed sae- } \\
\text { charimeter } \\
\text { reading } \\
\text { (4 dm tube) }\end{array}$ & $\begin{array}{c}{[\alpha]_{\mathrm{D}}^{20}} \\
\text { of } d \text {-gulose }\end{array}$ \\
\hline 10 & $\begin{array}{l}\circ S . \\
-0.75 \\
=.60 \\
=.55 \\
=.50 \\
-.45\end{array}$ & $\begin{array}{l}-20.5 \\
-16.4 \\
-15.0 \\
-13.6 \\
-12.3\end{array}$ & $\begin{array}{l}3 \\
9 \\
400 \\
\infty\end{array}$ & $\begin{array}{l}{ }^{\circ} S . \\
-1.95 \\
-2.00 \\
-1.95 \\
-1.95 \\
-1.95\end{array}$ & $\begin{array}{l}-26.6 \\
-27.3 \\
-26.6 \\
-26.6 \\
-26.6\end{array}$ \\
\hline
\end{tabular}

1 The solution of $d$-gulose was obtained by removing the $\mathrm{CaCl}_{2}$ fiom $\alpha-d$-gulose $\mathrm{CaCl}_{2} \cdot \mathrm{H}_{2} \mathrm{O} \quad(1.3947 \mathrm{~g}$ in a final volume of $25.6 \mathrm{ml}$ ). This solution gave a rotation of $-4.78^{\circ} \mathrm{S}$. in a $2 \mathrm{dm}$ tube, $[\alpha]_{\mathrm{D}}^{20}=-26.1$.

${ }_{2}^{2}$ The ealeium chloride solution was prepared by dissolving $5 \mathrm{~g}$ of anhydrous $\mathrm{CaCl}_{2}$ in suffeient water to give $100 \mathrm{ml}$. The mutarotation constants are not recorded because the salt contained a small amount of alkali which accelerated the mutarotation.

$$
4754^{\circ}-30-16
$$


TABLE 6.-Mutarotation of d-gulose $\mathrm{CaCl}_{2} \cdot \mathrm{H}_{2} \mathrm{O}$ after dilution with water at $18.5^{\circ} \mathrm{C}$

[10 $\mathrm{ml}$ of the solution shown in Table 3 containing $2.6592 \mathrm{~g} d$-gulose $\mathrm{CaCl}_{2} \cdot \mathrm{H}_{2} \mathrm{O}$ in $25 \mathrm{ml}$ wcre diluted to $100 \mathrm{ml}$ with water and the mutarotation was followed in a $4 \mathrm{dm}$ tube. Concentration $=1.0637 \mathrm{~g}$ in 100 $\mathrm{ml}$ of solution]

\begin{tabular}{|c|c|c|c|}
\hline $\begin{array}{l}\text { Time after adding water } \\
\text { (in minutes) }\end{array}$ & $\begin{array}{l}\text { Observcd sac- } \\
\text { charimeter } \\
\text { reading }\end{array}$ & $\begin{array}{c}{[\alpha]_{D}^{18.5}} \\
\text { of compound }\end{array}$ & $k_{1}+k_{2}$ \\
\hline $\begin{array}{l}0 \\
3.5 \\
10\end{array}$ & $\begin{array}{l}\circ S . \\
-1.0 \\
-1.05 \\
-1.15 \\
-1.25\end{array}$ & $\begin{array}{l}1(7.3) \\
-8.1 \\
-8.5 \\
-9.4 \\
-10.2\end{array}$ & $\begin{array}{l}0.019 \\
.013 \\
.015 \\
.017\end{array}$ \\
\hline $\begin{array}{l}25 \\
30 \\
50 \\
50\end{array}$ & $\begin{array}{l}-1.45 \\
-1.55 \\
-1.58 \\
-1.65 \\
-1.78\end{array}$ & $\begin{array}{l}-11.8 \\
-12.6 \\
-12.9 \\
-13.4 \\
-14.5\end{array}$ & $\begin{array}{r}.020 \\
.018 \\
0.17 \\
\\
0.0 .\end{array}$ \\
\hline Average & & & .017 \\
\hline
\end{tabular}

1 Calculated as given under Table 1, p. 744 , using the following values: $k_{1}+k_{2}=0.017 ; r=-8.1 ; r \infty=-$ $14.55 ; t=3$.

\section{TABLE 7.-Mutarotation of $d$-gulose $\mathrm{CaCl}_{2} \cdot \mathrm{H}_{2} \mathrm{O}$ after dilution with ethyl alcohol at $18.5^{\circ} \mathrm{C}$}

[10 $\mathrm{ml}$ of the solution shown in Table 2 containing $2.6592 \mathrm{~g} d$-gulose $\mathrm{CaCl}_{2} \cdot \mathrm{H}_{2} \mathrm{O}$ in $25 \mathrm{ml}$ were diluted to $50 \mathrm{ml}$ with absolutc ethyl alcohol, and the mutarotation was followed in a $2 \mathrm{dm}$ tube. Concentration= $2.1274 \mathrm{~g}$ in $100 \mathrm{ml}$ of solution]

\begin{tabular}{|c|c|c|c|}
\hline $\begin{array}{l}\text { Time after adding alcohol } \\
\text { (in minutes) }\end{array}$ & $\begin{array}{l}\text { Observed sac- } \\
\text { charimeter } \\
\text { reading }\end{array}$ & $\begin{array}{c}{[\alpha]_{\mathrm{D}}^{18.5}} \\
\text { of compound }\end{array}$ & $k_{1}+k_{2}$ \\
\hline & ${ }^{\circ} \mathrm{S}$. & \multirow{2}{*}{$\begin{array}{c}1(-7.4) \\
-6.9 \\
-6.1 \\
-4.9 \\
-4.1\end{array}$} & \\
\hline $\begin{array}{l}2 \\
4--- \\
8 \\
12--\end{array}$ & $\begin{array}{l}-0.85 \\
=.75 \\
=.60 \\
-.50\end{array}$ & & $\begin{array}{c}2(0.012) \\
.011 \\
.009\end{array}$ \\
\hline $\begin{array}{l}22 \\
33 \\
44 \\
75\end{array}$ & $\begin{array}{l}-.40 \\
\bar{T} .13 \\
+.10 \\
+.40 \\
+.95\end{array}$ & $\begin{array}{l}-3.3 \\
-1.1 \\
+\quad .8 \\
+3.3 \\
+7.7\end{array}$ & $\begin{array}{r}.006 \\
.007 \\
.008 \\
.007 \\
\end{array}$ \\
\hline Average .... & & & .008 \\
\hline
\end{tabular}

1 Calculated as given under Table 1, p. 744, using the following values: $k_{1}+k_{2}=0.008 ; r=-6.9 ; t=2$ : $r \omega=+7.7$. The calculated value agrees within the experimental error with the specific rotation of the solution $(-7.3)$ prior to dilution.

2 The temperature rose slightly upon adding the alcohcl to the aqueous solution, which may account for the higher values of $k_{1}+k_{2}$ obtained for the first 10 minutes.

\section{TABLE 8.-Variation in rotation of $\alpha$ - $d$-gulose $\mathrm{CaCl}_{2} \cdot \mathrm{H}_{2} \mathrm{O}$ with concentration}

\begin{tabular}{|c|c|c|c|c|c|c|}
\hline $\begin{array}{l}\alpha-d-G \text {-Gulose } \\
\mathrm{CaCl}_{2} \cdot \mathrm{H}_{2} \mathrm{O}\end{array}$ & $\begin{array}{c}\text { Concentra- } \\
\text { tion of } \\
\mathrm{CaCl}_{2}\end{array}$ & $\begin{array}{l}\text { Initial } \\
{[\boldsymbol{\alpha}]_{\mathrm{D}}^{20}}\end{array}$ & $\begin{array}{c}\text { Equilibrium } \\
{[\alpha]_{D}^{20}}\end{array}$ & 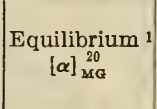 & $\begin{array}{c}\text { Rotation } \\
\text { calculated by } \\
{[\alpha]_{\mathrm{D}}^{20}=} \\
-15.4+0.78 \mathrm{C} .\end{array}$ & $\begin{array}{c}\text { Per cent }{ }^{2} \\
\text { undissociated } \\
\alpha \text {-d-gulose } \\
\mathrm{CaCl}_{2} \cdot \mathrm{H}_{2} \mathrm{O}\end{array}$ \\
\hline $\begin{array}{r}g / 100 \mathrm{ml} \\
10.6368 \\
5.1544 \\
4.4640 \\
2.3592 \\
1.5640 \\
.8856\end{array}$ & $\begin{array}{c}g / 100 \mathrm{ml} \\
3.82 \\
1.85 \\
1.60 \\
.85 \\
.56 \\
.32\end{array}$ & $\begin{array}{r}+37.7 \\
+37.9 \\
+37.6 \\
+38.0 \\
+37.3 \\
+36.9\end{array}$ & $\begin{array}{r}-7.3 \\
-11.1 \\
-11.6 \\
-13.4 \\
-14.4 \\
-14.9\end{array}$ & $\begin{array}{r}-8.79 \\
-13.99 \\
-16.21 \\
-17.53\end{array}$ & $\begin{array}{r}-7.1 \\
-11.4 \\
-11.9 \\
-13.6 \\
-14.2 \\
-14.7\end{array}$ & $\begin{array}{r}15.3 \\
8.1 \\
7.2 \\
3.8 \\
1.9 \\
.9\end{array}$ \\
\hline Average_- & & +37.7 & & & & \\
\hline
\end{tabular}

1 As a matter of record the rotations were measured for light of two wave lengths. $[\alpha]_{D}^{20}$ was determined from observations with a Bates saccharimeter using the conversion factor $0.3462 ;[\alpha]_{M G}^{20}$ was determined from observations with a polariscope using the mercury green line $(\lambda=546)$ as a source of light. The difference in rotations with light of different wave lengths is not abnormal.

Approximate estimation as given on p. 751 .

3 Omitted from the average. 


\section{EQUILIBRIUM ROTATION OF $d$-GULOSE $\mathrm{CaCl}_{2} \cdot \mathrm{H}_{2} \mathrm{O}$}

In the preceding paragraph under Table 8 it is seen that the "initial rotation" of $\alpha$-d-gulose $\mathrm{CaCl}_{2} \cdot \mathrm{H}_{2} \mathrm{O}$ is not influenced markediy by variations in the concentration of the compound; while in the same table it is shown that the equilibrium rotation varies from -14.9 to -7.3 when the concentration of $d$-gulose $\mathrm{CaCl}_{2} \cdot \mathrm{H}_{2} \mathrm{O}$ is increased approximately from 1 to 10 per cent. The equilibrium rotation of the pure sugar in the absence of calcium chloride does not vary greatly, as shown in column 6 of Table 5 ; thus a solution containing $3.1740 \mathrm{~g} d$-gulose in $100 \mathrm{ml}$ gave $[\alpha]_{\mathrm{D}}^{20}=-26.1 ; 5 \mathrm{ml}$ of this solution when diluted to $25 \mathrm{ml}$ with water did not exhibit mutarutation and gave $[\alpha]_{D}^{20}=-26.6 .^{13}$ Hence, we may conclude that the large variations in the equilibrium rotation of $\alpha$ - $d$-gulose $\mathrm{CaCl}_{2} \cdot \mathrm{H}_{2} \mathrm{O}$ are not produced by the variation in the concentration of the sugar, but rather by the calcium chloride.

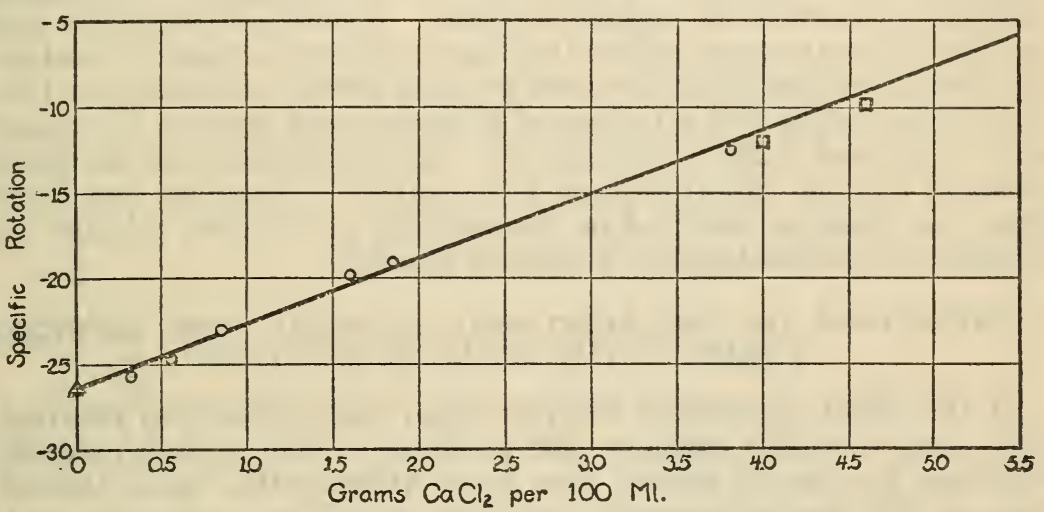

FigURE 2.-Effect of calcium chloride upon the equilibrium rotation of $d$-gulose

The variation in the equilibrium rotation of $d$-gulose calcium chloride is nearly a linear function of its concentration which may be expressed by the following empirical equation:

$$
[\alpha]_{D}^{20}=-15.4^{\circ}+0.78 C
$$

where $C$ is the concentration of $d$-gulose $\mathrm{CaCl}_{2} \cdot \mathrm{H}_{2} \mathrm{O}$ in g per $100 \mathrm{ml}$. This equation may be converted by equivalent weights to express the equilibrium rotation of $d$-gulose in the presence of calcium chloride. The following equation is thus obtained:

$$
[\alpha]_{\mathrm{D}}^{20}=-26.4+3.73 m
$$

where $[\alpha]_{D}^{20}$ is the equilibrium specific rotation of $d$-gulose and $m$ is the number of grams of anhydrous calcium chloride per $100 \mathrm{ml}$ of solution.

The linear curve in Figure 2 represents the latter equation; the points marked with circles represent the rotations of $d$-gulose which

${ }_{13}$ The value $[\alpha]_{\mathrm{D}}^{20}=-26.4$, which was obtained for the solution given in Table 1 , agrees within the experimental error with the values given above. The value of $[\alpha]_{\mathrm{D}}^{20}=-26.4$ for $d$-gulose is equivalent, to $[\alpha]_{\mathrm{D}}^{20}=-15.4$ for $d$-gulose $\mathrm{CaCl}_{2} \cdot \mathrm{H}_{2} \mathrm{O}$. 
were obtained from different concentrations of the double compound of $d$-gulose and calcium chloride; the squares represent the rotations of d-gulose to which calcium chloride had been added, and the point marked with a triangle represents the rotation of a pure solution of $d$-gulose as obtained after removing the calcium chloride with silver oxalate.

It is interesting to compare the effect of calcium chloride upon the equilibrium rotation of $d$-gulose with its effect upon the rotations of other sugars. Murschhauser ${ }^{14}$ found the specific rotation of $d$-gulose to be $+52.8^{\circ}$ in water and $+56.0^{\circ}$ in $2 N$ calcium chloride solution. The difference in rotation (3.2) is equivalent to an increase of 0.29 for each gram of calcium chloride per $100 \mathrm{ml}$ of solution. Jackson and Gillis ${ }^{15}$ found the rotation in ${ }^{\circ} S$ of a saccharimetric normal sucrose solution containing $m$ grams of calcium chloride per $100 \mathrm{ml}$ of solution is given by the equation: $R=100-0.339 \mathrm{~m}$. This expression is equivalent to $[\alpha]_{\mathrm{D}}^{20}=66.6^{\circ}-0.226 \mathrm{~m}$, where $[\alpha]_{\mathrm{D}}^{20}$ is the specific rotation of sucrose in angular degrees. A comparison of the values for the different sugars shows that the equilibrium specific rotation of $d$-gulose is changed $3.73^{\circ}$ for each gram of calcium chloride per $100 \mathrm{ml}$ of solution, while the rotations of $d$ glucose and sucrose are changed only $0.29^{\circ}$ and $0.226^{\circ}$, respectively. An explanation of the marked effect of calcium chloride upon the rotation of $d$-gulose was derived from the changes observed in the rotation of a gulose solution upon altering the concentration of calcium chloride.

\section{VARIATIONS IN THE EQUILIBRIA BETWEEN THE DIFFERENT FORMS OF THE SUGAR IN SOLUTION}

If the effect of calcium chloride upon the equilibrium rotation of the sugar were due solely to the presence of the calcium chloride in solution, one would expect that upon altering the concentration of the salt the change in specific rotation would be practically instantaneous. However, if the calcium chloride altered the equilibrium between the different forms of the sugar in solution, the change in rotation would be slow and would occur at the same rate as the mutarotation of the sugar. A change in concentration of the calcium chloride and the sugar is easily obtained by diluting a concentrated solution. Measurements of optical rotation, after diluting a solution of $d$-gulose calcium chloride, clearly show a slow mutarotation, which follows approximately the course of a monomolecular reaction.

Figure 3 shows the mutarotation of the solution of $\alpha$ - $d$-gulose $\mathrm{CaCl}_{2} \cdot \mathrm{H}_{2} \mathrm{O}$ which was given in Table 3 . After equilibrium was reached, a portion of the solution was diluted to 10 volumes with water. The mutarotation of this diluted solution is given in Table 6 and is illustrated in Figure 3 by the portion of the curve marked "diluted with water." Another portion of the solution in equilibrium was diluted to 5 volumes with absolute ethyl alcohol; the mutarotation of this portion is given in Table 7 and is illustrated in Figure 3 by the portion of the curve marked "diluted with alcohol." The solution upon dilution with water slowly becomes more levorotatory, while the solution upon dilution with alcohol slowly becomes less

14 Murschhauser, Biochem. Z., 136, p. 66; 1923.

is Jackson and Gillis, B. S. Sci. Puper No. 375, p. 164; 1920. 
levorotatory. The extrapolated initial specific rotations of the portions diluted with water, $\left([\alpha]_{\mathrm{D}}^{20}=-7.3\right)$, and with alcohol, $([\alpha]]_{\mathrm{D}}^{20}=$ $-7.4)$, agree with the observed rotation $\left([\alpha]_{\mathrm{D}}^{20}=-7.3\right)$ prior to dilution; that is, the solutions had practically the same specific rotation immediately after dilution as they had before dilution. The rate at which the rotation changes after diluting the concentrated solution with water $\left(k_{1}+k_{2}=0.017\right.$ at $18.5^{\circ} \mathrm{C}$.) agrees with the rate of mutarotation of $\alpha$ - $d$-gulose $\mathrm{CaCl}_{2} \cdot \mathrm{H}_{2} \mathrm{O}\left(k_{1}+k_{2}=0.018\right.$ at $18.5^{\circ} \mathrm{C}$.), which indicates that the reaction is similar to the mutarotation of the sugar. As would be expected, the rotation of the portion diluted with alcohol changes more slowly than the rotation of the portion diluted with water. But of particular importance is the fact that a different equilibrium rotation $\left([\alpha]_{\mathrm{D}}^{20}=+7.7\right)$ is reached from that given by an aqueous solution of similar concentration ${ }^{16}\left([\alpha]{ }_{D}^{20}=-13.7\right)$, which indicates that the equilibrium existing in an alcoholic solution of $d$-gulose calcium chloride is different from the equilibrium existing in a water solution.

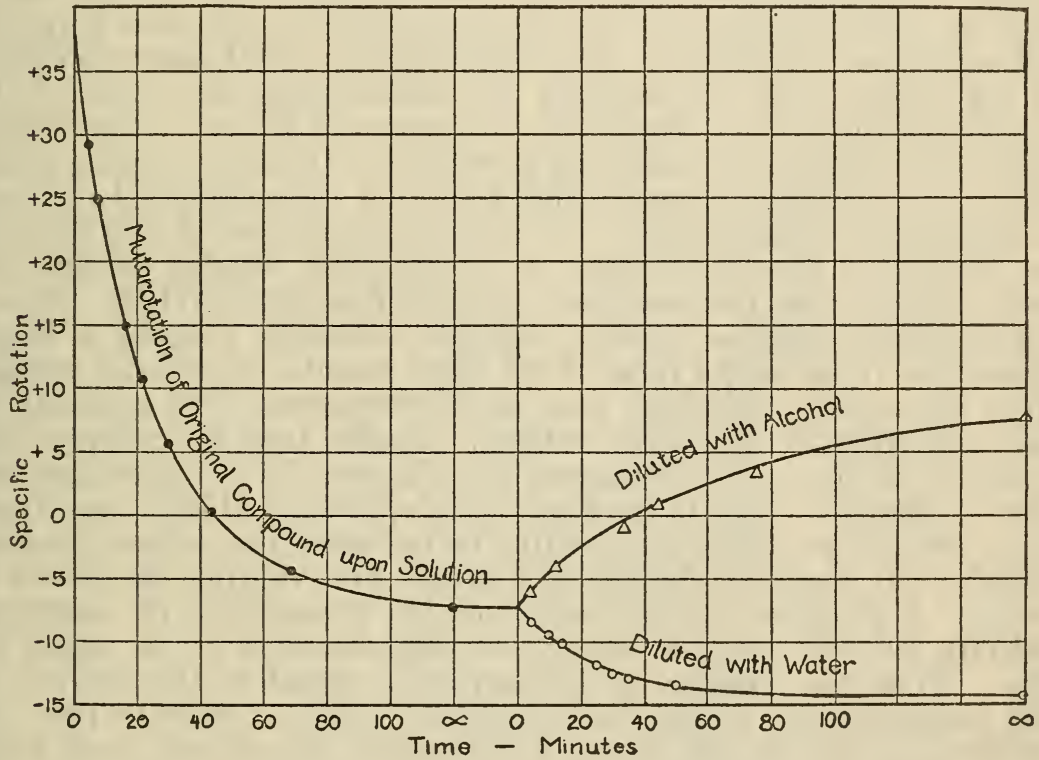

FIGURE 3.-The mutarotation of d-gulose $\mathrm{CaCl}_{2} \cdot \mathrm{H}_{2} \mathrm{O}$

\section{DISSOCIATION OF $a-d$-GULOSE $\mathrm{CaCl}_{2}$}

The mutarotation which follows a change in the concentration of $d$-gulose calcium chloride indicates that in some manner the sugar equilibrium is disturbed by the change in concentration. Probably a sugar solution contains a number of isomeric ring forms in equilibrium. ${ }^{17}$ The addition of a salt to the system further complicates the condition by forming molecular compounds with the various isomeric forms of the sugar. At this time it is not possible to state to what extent the various isomeric compounds actually exist, but

17 Cramer, "Les Sucres and Leurs Derives," p. 172, Gaston Doin \& Co., Paris; 1927. 
some of the molecular compounds may be obtained in the crystalline state. ${ }^{18}$ It is probable that in dilute solution the compounds are largely dissociated into the sugar and calcium chloride. The degree of dissociation is influenced by the concentration and the solvent; a change in the concentration or solvent alters the relative amounts of dissociated and undissociated compounds. The dissociation just mentioned should not be confused with the electrolytic dissociation of calcium chloride. The sugar may be associated with calcium chloride molecules, calcium ions or chloride ions; in the discussion that follows, the exact nature of the compound is immaterial though it is spoken of as a calcium chloride compound. According to this concept there are at all dilutions of $d$-gulose $\mathrm{CaCl}_{2}$ less than infinite, two classes of substances: (1) Associated gulose calcium chloride, and (2) completely dissociated $\alpha$-and $\beta$ - $d$-gulose in equilibrium. The rotation of the solution is equal to the rotation of the undissociated $d$-gulose calcium chloride plus the rotation of the completely dissociated $\alpha$-and $\beta$ - $d$-gulose in equilibrium. If a calcium chloride compound of a particular form of a sugar is present in a much larger quantity than the calcium chloride compounds of the other forms of the sugar upon diluting a concentrated solution that particular form of the sugar would be liberated (by dissociation) in excess of the equilibrium proportion and mutarotation would follow. It is evident that if only one double compound were present the mutarotation which followed a change in concentration would be a measure of the change in the degree of dissociation. A concentrated gulose calcium chloride solution upon dilution exhibits a mutarotation similar in direction and rate to the mutarotation of $\alpha-d$-gulose $\mathrm{CaCl}_{2} \cdot \mathrm{H}_{2} \mathrm{O}$. Hence, concentrated $d$-gulose calcium chloride solutions contain a larger proportion of the alpha form of the sugar (combined in some manner with the calcium chloride) than dilute solutions. The quantity of the undissociated $\alpha$ - $d$-gulose calcium chloride may be roughly estimated from the optical rotations, if we assume as an approximation that (1) the alpha form of the sugar is the only form which is associated with the salt in sufficient quantity to influence the optical rotation greatly; (2) that the change of rotation with dilution as shown in column 4 of Table 8 is due solely to the dissociation of $\alpha$-d-gulose calcium chloride and the subsequent mutarotation of the sugar set free. Thus the rotation of the solution is equal to the rotation of the undissociated portion of $\alpha$ - $d$-gulose calcium chloride plus the rotation of the portion which is completely dissociated, and exists as an alpha beta equilibrium mixture. It was previously shown in column 3, Table 8 , that the specific rotation of $\alpha-d$-gulose $\mathrm{CaCl}_{2} \cdot \mathrm{H}_{2} \mathrm{O}$ is +37.7 , and that it is fairly independent of dilution or the concentration of calcium chloride. It was shown in paragraph 2 that the specific rotation of $\alpha$-and $\beta$ - $d$-gulose in equilibrium is also nearly independent of concentration and when expressed on the weight of $d$-gulose (180) equals -26.4 which is equivalent to -15.4 expressed on the weight of the compound, $\alpha-d$-gulose $\mathrm{CaCl}_{2} \cdot \mathrm{H}_{2} \mathrm{O}$ (309). As shown in column 4 , Table 8 , the equilibrium specific rotation of $d$-gulose $\mathrm{CaCl}_{2} \cdot \mathrm{H}_{2} \mathrm{O}$ approaches with dilution the value just given; hence,

${ }_{18} \mathrm{~J}$. K. Dale obtained two crystalline calcium chloride compounds of $d$-mannose which he believes are ring isomers. See footnote $8, \mathrm{p}, 742$. 
the specific rotation at infinite dilution is taken as -15.4 . If we let $X$ equal the dissociated fraction of $\alpha$ - $d$-gulose $\mathrm{CaCl}_{2} \cdot \mathrm{H}_{2} \mathrm{O}$ then, $(1-X)$ equals the undissociated fraction and the specific rotation of the solution is given by the following equation:

$$
[\alpha]_{\mathrm{D}}=37.7(1-X)-15.4 X
$$

The values given in column 7 , Table 8 , for the undissociated $\alpha$ - $d$-gulose $\mathrm{CaCl}_{2}$ were obtained from the data given in column 4 of the same table by the above equation. According to this method of calculation the undissociated portion of $\alpha$-d-gulose $\mathrm{CaCl}_{2} \cdot \mathrm{H}_{2} \mathrm{O}$ at equilibrium in water solution increased from 0.9 to 15.3 per cent when the concentration of calcium chloride was increased from 0.32 to $3.82 \mathrm{~g}$ per $100 \mathrm{ml}$. (Table 8 .)

\section{CRYSTALLIZATION OF $\alpha$ - $d$-GULOSE $\mathrm{CaCl}_{2} \cdot \mathrm{H}_{2} \mathrm{O}$}

The dependence of the degree of dissociation of $\alpha$ - $d$-gulose $\mathrm{CaCl}_{2} \cdot \mathrm{H}_{2} \mathrm{O}$ upon the concentration of calcium chloride and the solvent points to the conditions favorable for the crystallization of that substance. Increasing concentrations of both calcium chloride and ethyl alcohol shift the equilibrium rotation of $d$-gulose toward the rotation of $\alpha$-d $d$-gulose $\mathrm{CaCl}_{2} \cdot \mathrm{H}_{2} \mathrm{O}$ which leads to the supposition that an excess of calcium chloride in concentrated alcoholic solution is most favorable for the separation of $\alpha$-d-gulose $\mathrm{CaCl}_{2} \cdot \mathrm{H}_{2} \mathrm{O}$. An application of these conditions resulted in a very marked improvement in the original method for the preparation of that product.

A concentrated aqueous $d$-gulose sirup is diluted with a solution of at least two equivalents of anhydrous calcium chloride dissolved in 95 per cent ethyl alcohol. After a short time crystalline $\alpha-d$-gulose $\mathrm{CaCl}_{2} \cdot \mathrm{H}_{2} \mathrm{O}$ separates. Frequently crystallization does not start at once, but usually it may be started by carefully warming the solution on a steam bath, or, if necessary, by nucleation. A second crop of crystals may be obtained by saturating the cold alcoholic solution with ether and allowing to stand for several days. Although concentrated gulose solutions are precipitated with 95 per cent ethyl alcohol they are almost miscible with alcoholic solutions of calcium chloride. The use of the alcoholic calcium chloride solution gives a good yield of crystalline product which is difficult to obtain with aqueous solutions. The improved method is so satisfactory that the salt may be crystallized from the crude $d$-gulose sirup obtained from the reduction of gulonic lactone without previous purification by means of the phenylhydrazone. If it is desired to prepare a considerable quantity of $\alpha-d$-gulose the elimination of this step is of considerable importance because phenylhydrazine is expensive and the filtration of $d$-gulose phenylhydrazone is frequently very slow. Since the new compound, $\alpha$-d-gulose $\mathrm{CaCl}_{2} \cdot \mathrm{H}_{2} \mathrm{O}$, may be used directly for the preparation of many derivatives, it should now be possible to extend our knowledge of the chemistry of the gulose series. ${ }^{19}$

19 The author has prepared a number of crystalline derivatives of $d$-gulose from $\alpha$-d-gulose $\mathrm{CaCl}_{2} \cdot \mathrm{H}_{2} \mathrm{O}$, which will be reported in subsequent publications. 


\section{EXPERIMENTAL DETAILS}

\section{PREPARATION OF CRUDE $d$-GULOSE}

The method which was used for the preparation of the crude $d$-gulose was essentially that of Fischer and Stahel. ${ }^{20}$ Ninety grams gulonic lactone dissolved in $900 \mathrm{ml}$ of water were placed in a 10 -liter pail and cooled to and maintained at $0^{\circ} \mathrm{C}$. by an ice-salt mixture. Simultaneously small portions of $2 N$ sulphuric acid and 2.5 per cent sodium amalgam were added while the solution was vigorously stirred. with a mechanical stirrer. The solution was held slightly acid (purple to congo red paper) by adjusting the rates at which the sodium amalgam and sulphuric acid were added. A total of $2,000 \mathrm{~g}$ of sodium amalgam were added which required about four hours. When the sodium amalgam was exhausted as shown by the fact that the addition of sulphuric acid was no longer necessary to maintain the desired acidity, the aqueous solution was decanted from the mercury and filtered. The filtrate was concentrated in vacuo to about $500 \mathrm{ml}$. It was then diluted with an equal volume of ethyl alcohol and the sodium sulphate was separated by filtration. The filtrate was made definitely acid (blue to congo red paper) with $2 \mathrm{~N}$ sulphuric acid and then concentrated in vacuo to a thick sirup. This sirup was diluted with an equal volume of methyl alcohol and seeded with gulonic lactone. After two days $25 \mathrm{~g}$ of crystalline gulonic lactone were reclaimed. The alcohol was distilled from the mother liquor, which, after diluting slightly with water, was made alkaline (pink to phenolphthalein) with $2 N$ sodium hydroxide. Care was taken to neutralize completely the remaining gulonic lactone. After the solution was adjusted to neutrality (colorless to phenolphthalein) it was concentrated in vacuo to a thick sirup which was then poured into 10 volumes of hot 95 per cent ethyl alcohol. The alcoholic solution was decanted and the residue was thoroughly extracted with several portions of hot 95 per cent alcohol. After evaporating the alcohol in vacuo, crude gulose sirup $(40 \mathrm{~g})$ was obtained which still contained some inorganic salts, but which was suitable for the preparation of gulose phenylhydrazone, or $\alpha$ - $d$-gulose $\mathrm{CaCl}_{2} \cdot \mathrm{H}_{2} \mathrm{O}$.

\section{PURIFICATION OF CRUDE GULOSE BY ITS PHENYLHYDRAZONE}

The sample of $\alpha$-d-gulose $\mathrm{CaCl}_{2} \cdot \mathrm{H}_{2} \mathrm{O}$ which was used for the determination of its optical properties was prepared from a gulose sirup obtained from $d$-gulose phenylhydrazone by the method of Blanksma and van Ekenstein. ${ }^{21}$

Twenty grams of the crude gulose sirup were dissolved in $50 \mathrm{ml}$ of water containing a few drops of acetic acid and then mixed with $12 \mathrm{~g}$ of phenylhydrazine. The reaction occurred quickly and a semisolid product resulted which was kept stirred until the reaction was complete. After about one hour the product was filtered by suction and washed with water. It was sucked as dry as possible and then washed with ether. The hydrazone is very soluble in dilute alcohol, but is readily recrystallized from absolute alcohol. About $18 \mathrm{~g}$ of recrystallized gulose phenylhydrazone were obtained. The phenylhydrazine was removed by refluxing $18 \mathrm{~g}$ of gulose phenyl- 
hydrazone with $15 \mathrm{ml}$ of benzaldehyde, $18 \mathrm{ml}$ of alcohol, and $15 \mathrm{ml}$ of water. The solution was filtered and the filtrate extracted several times with ether to remove the excess benzaldehyde and the benzaldehyde phenylhydrazone. After the addition of about $1 \mathrm{~g}$ of decolorizing carbon the solution was filtered and evaporated. Attempts were made in vain to bring the resulting colorless gulose sirup to crystallization.

\section{PREPARATION OF $\alpha$ - $d$-GULOSE $\mathrm{CaCl}_{2} \cdot \mathrm{H}_{2} \mathrm{O}$ FROM THE GULOSE SIRUP OBTAINED FROM THE PHENYLHYDRAZONE}

Twenty grams of thick gulose sirup prepared from $d$-gulose phenylhydrazone were mixed with a solution of $30 \mathrm{~g}$ of pure crystalline calcium chloride in $50 \mathrm{ml}$ of water. The solution was evaporated under reduced pressure to a thick sirup, which, when allowed to stand in a desicactor over sulphuric acid, crystallized spontaneously. After several days the mixture was diluted with about $150 \mathrm{ml}$ of absolute alcohol and the crystals $(14 \mathrm{~g})$ were separated by filtration. After concentration, a second crop of crystals $(5 \mathrm{~g})$ was obtained. The crystals are very difficultly soluble in hot ethyl alcohol and practically insoluble in ether and other similar organic solvents. The salt may be recrystallized by dissolving in a very small amount of hot water; on cooling, the crystals separate from the thick mother liquor which is diluted with absolute alcohol to facilitate filtration. A second crop of less pure gulose calcium chloride may be obtained by the addition of dry ether to the mother liquor. For analysis the product was recrystallized five times and dried to constant weight (18 hours) at $40^{\circ} \mathrm{C}$. in vacuo. Analysis calculated for $\mathrm{C}_{6} \mathrm{H}_{12} \mathrm{O}_{6} \mathrm{CaCl}_{2} \cdot \mathrm{H}_{2} \mathrm{O}: \mathrm{C}, 23.29$; $\mathrm{H}, 4.57$; Ca, 12.96; Cl, 22.94. Found: C, 23.25; H, 4.55; Ca, 12.99; Cl, 22.82. Check sample found: $\mathrm{Ca}, 12.99 ; \mathrm{Cl}, 22.80$. Loss on drying two hours at $100^{\circ}$ in vacuo: Subs., 1.0725 ; loss, 0.0003 . It decomposes with the evolution of gas and fusion at about $205^{\circ} \mathrm{C}$.

\section{OPTICAL ROTATION OF $\alpha$-d-GULOSE}

The determination of the optical rotation of $\alpha$ - $d$-gulose was conducted in a constant temperature room at $20^{\circ} \mathrm{C}$. $1.2238 \mathrm{~g}$ of finely powdered $\alpha$-d-gulose $\mathrm{CaCl}_{2} \cdot \mathrm{H}_{2} \mathrm{O}$ and $2 \mathrm{~g}$ of freshly prepared dry silver oxalate ${ }^{22}$ were placed in a glass-stoppered flask and $24.9550 \mathrm{~g}$ of water were added from a pipette which had been calibrated and found to deliver that weight of water in 20 seconds. Preliminary experiments had shown that $1.2 \mathrm{~g}$ of finely powdered $\alpha$-d-gulose $\mathrm{CaCl}_{2} \cdot \mathrm{H}_{2} \mathrm{O}$ could be dissolved in $25 \mathrm{ml}$ of water in about 20 seconds. The time was measured from the moment when it was believed that half of the sugar was dissolved. This was about 5 seconds after the addition of the first water when about half of the water had drained from the pipette. The mean time when the mutarotation started is probably within 5 or 10 seconds of the time thus estimated. The flask containing the gulose calcium chloride and silver oxalate was shaken 2.5 minutes, then $0.2 \mathrm{~g}$ of decolorizing carbon (Norit) was added and the solution filtered. The rotation of the filtered solution was read in a $2 \mathrm{dm}$ "Landolt inversion tube" with a Bates saccharimeter. Initially the rotation was changing about $0.5^{\circ} \mathrm{S}$ per minute;

${ }^{22}$ The silver oxalate was prepared from silver nitrate and slightly acidified (oxalic acid) sodium oxalate. It was dried at $40^{\circ}$ in vacuo and protected from light, 
consequently the error in the reading is relatively large (possibly $0.1^{\circ}$ $\mathrm{S})$. The temperature of the solution was measured at intervals; after $6,13,18,25,30$, and 50 minutes the following temperatures were observed: $19.9^{\circ}, 20.0^{\circ}, 20.1^{\circ}, 20.15^{\circ}$, and $20.15^{\circ}$. After completing the optical measurements qualitative tests were made on the solution for chlorides, calcium, and silver. The tests for chlorides and calcium were negative. A very faint opalescence was obtained with a drop of hydrochloric acid which indicated that a trace of a silver salt was in solution, but the amount was negligible. The density of the solution was determined with a picnometer which had a capacity of 10.686 $\mathrm{ml}$ at $20^{\circ} \mathrm{C}$. It held $10.7876 \mathrm{~g}$ of the solution at $20^{\circ} \mathrm{C}$. (weighted in air) which gives a density of 1.0095 . From the molecular weights, $1.2238 \mathrm{~g}$ of $\alpha$ - $d$-gulose $\mathrm{CaCl}_{2} \cdot \mathrm{H}_{2} \mathrm{O}$ is equivalent to $0.7130 \mathrm{~g}$ of gulose and $0.0713 \mathrm{~g}$ of $\mathrm{H}_{2} \mathrm{O}$. This water must be added to the water delivered from the pipette $(24.9550 \mathrm{~g})$ because it is liberated when the calcium chloride is removed. Thus $0.7130 \mathrm{~g}$ of $d$-gulose was contained in $25.0263 \mathrm{~g}$ of water, which gives $25.7393 \mathrm{~g}$ of solution. This is equivalent to $25.5 \mathrm{ml}$ of a solution of 1.0095 density. The values given in Table 1 were then calculated as explained in the footnotes. It should be noted that all the calcium chloride was removed in less than 2.5 minutes after the addition of water and that the rates of mutarotation of the $\mathrm{CaCl}_{2}$ compound, and the gulose solution are sufficiently near to each other that the initial rotation may be extrapolated to zero time.

\section{PREPARATION OF $\alpha$ - $d$-GULOSE $\mathrm{CaCl}_{2} \cdot \mathrm{H}_{2} \mathrm{O}$ FROM THE REDUCTION PRODUCT OF GULONIC LACTONE}

Twenty grams of the thick gulose sirup, which was prepared as given before ${ }^{21}$ were mixed with a solution of $30 \mathrm{~g}$ of anhydrous calcium chloride in $150 \mathrm{ml}$ of 95 per cent ethyl alcohol. A small quantity of amorphous material was precipitated which was removed by filtration. The clear filtrate was gently warmed and stirred. After a short time crystallization occurred. (The product usually crystallizes spontaneously, although with impure sirups nucleation and concentration is necessary.) About $20 \mathrm{~g}$ of crystalline $\alpha$-d-gulose $\mathrm{CaCl}_{2}$. $\mathrm{H}_{2} \mathrm{O}$ were obtained. By concentrating the filtrate to $50 \mathrm{ml}$, and saturating the sirup with ether, a second crop of crystals $(8 \mathrm{~g})$ was obtained. The final product, when prepared from sirups containing sodium salts, usually contains some sodium chloride which is difficult to remove. Hence, if one desires only a small quantity of a pure product it is usually advisable to start with a pure gulose solution, such as is obtained from $d$-gulose phenylhydrazone. But if a large quantity of material is desired, especially if a small quantity of sodium chloride is not objectionable, it is far easier to prepare it directly from the crude sirup.

\section{SUMMARY}

A crystalline calcium chloride compound of $\alpha$ - $d$-gulose $\left(\mathrm{C}_{6} \mathrm{H}_{12} \mathrm{O}_{6}\right.$ $\mathrm{CaCl}_{2} \cdot \mathrm{H}_{2} \mathrm{O}$ ) has been prepared, and its optical rotation studied. It exhibits mutarotation: The extrapolated initial specific rotation, $[\alpha]_{\mathrm{D}}^{20}=+37.7$; at equilibrium, $[\alpha]_{\mathrm{D}}^{20}=-15.4^{\circ}+0.78 C$., where $C$ is the concentration of $\alpha$-d-gulose $\mathrm{CaCl}_{2} \cdot \mathrm{H}_{2} \mathrm{O}$ in grams per $100 \mathrm{ml}$; the mutarotation coefficient, $k_{1}+k_{2}=0.0193$ at $20^{\circ} \mathrm{C}$. 
If the calcium chloride is removed from a freshly prepared solution of $\alpha$-d-gulose $\mathrm{CaCl}_{2} \cdot \mathrm{H}_{2} \mathrm{O}$ by means of silver oxalate, the resulting solution of pure $\alpha-d$-gulose shows a rate of mutarotation $\left(k_{1}+k_{2}=0.0206\right)$ close to that given by $d$-gulose calcium chloride and near to that given by the closely related sugar $d$-mannose. The molecular rotation of $\alpha$ - $d$-gulose was found to be $+11,100$, which differs only slightly more than the probable error from the molecular rotation $+11,650$ of $\alpha$-d-gulose $\mathrm{CaCl}_{2} \cdot \mathrm{H}_{2} \mathrm{O}$.

The equilibrium rotation of $d$-gulose in the absence of calcium chloride is not appreciably altered by small changes in the concentration of the sugar, but the equilibrium rotation of $d$-guluse $\mathrm{CaCl}_{2}$. $\mathrm{H}_{2} \mathrm{O}$ is greatly altered by small changes in the concentration of the compound. Concentrated solutions of the calcium chloride compound exhibit on dilution with water a mutarotation rate approximately equal to the mutarotation rate of $d$-gulose. This mutarotation shows that the salt changes the equilibrium rotation of $d$-gulose by altering in some manner the relative amounts of the different forms of the sugar in solution.

\section{ACKNOWLEDGMENT}

The author expresses his appreciation to F. P. Phelps, of this pureau, who kindly made the photograph given in Figure 1; to C.S. Hudson, who first suggested a study of this sugar; to R. F. Jackson and to other members of the polarimetry section, who have aided in the course of this investigation.

Washington, April 28, 1930. 